\title{
NUMERICAL CFD SIMULATION AND TEST CORRELATION IN A FLIGHT PROJECT ENVIRONMENT
}

\author{
K. K. Gupta \\ NASA Armstrong Flight Research Center \\ Edwards, CA, USA
}

\author{
A. H. Ibrahim \\ Norfolk State University \\ Norfolk, VA, USA
}

\author{
S. F. Lung \\ Jacobs Technology \\ Edwards, CA, USA
}

\begin{abstract}
This paper presents detailed description of a novel CFD procedure and comparison of its solution results to that obtained by other available CFD codes as well as actual flight and wind tunnel test data pertaining to the GIII aircraft, currently undergoing flight testing at AFRC.
\end{abstract}

\section{INTRODUCTION}

Two in-house ${ }^{1}$ software as well as a number of commercially ${ }^{2-6}$ available CFD codes were used to analyze the problem, for comparison purposes. In this process both finite volume and finite element discretization were used for Euler and Navier-Stokes simulations. Both unstructured and structured grids were employed, as appropriate and solutions were derived for Mach 0.701 and angle of attack $\alpha=3.92$ degree.

Extensive flight tests were performed for validation purposes. Also these tests were complimented with detailed wind tunnel simulations. All such test results are compared with the numerical solution data obtained by the various CFD codes. Associated finite difference ${ }^{7}$ and finite volume ${ }^{8,9}$ techniques are well described in the literature ${ }^{10,11}$. The finite element technique $^{12}$ for the discretization of fluid flow employs unstructured mesh and is based on a Taylor-Galerkin procedure $^{13-15}$.

A description of the finite element fluids solver is presented in some detail. It pertains to the solution of viscous flow represented by the Navier-Stokes formulation. An unstructured grid is used for domain decomposition.

The one equation model (Ref. 16) has been adapted for turbulence modelling. In this process both the viscous stresses pertaining to the linear viscous flow and the flux in the energy equation, are duly modified.

It is then followed by detailed results of analyses which are next compared with actual flight test and wind tunnel simulation results. These results indicate that most CFD solutions compare reasonably well with the test data. The FE solutions in particular prove to be efficient and accurate and the related software are available for public use.

Finally, some summarizations and discussions of the current effort is given in the 'Concluding Remarks' section.

\section{NOMENCLATURE}

$\begin{array}{ll}\text { AFRC } & =\text { Armstrong Flight Research Center } \\ \mathrm{CFD} & =\text { Computational Fluid Dynamics } \\ \mathrm{FE} & =\text { Finite Element } \\ \Delta t & =\text { time step } \\ \rho & =\text { Density } \\ \mu & =\text { Dynamic viscosity } \\ \sigma & =\text { Viscous stress tensor } \\ \mathrm{u} & =\text { free stream velocity } \\ \mathrm{E} & =\text { Total energy } \\ \mathbf{a} & =\text { Shape function } \\ \boldsymbol{v} & =\text { Conservation variable } \\ \boldsymbol{f} & =\text { Convection } \\ \boldsymbol{g} & =\text { Diffusion }\end{array}$




$\begin{array}{ll}k & =\text { Thermal conductivity } \\ p & =\text { Pressure } \\ \mathbf{M} & =\text { Mass matrix } \\ \mathbf{K} & =\text { Convection matrix } \\ \operatorname{Re} & =\text { Reynolds number } \\ \operatorname{Pr} & =\text { Prandtl number }\end{array}$

\section{PROCEDURE}

The Navier-Stokes equation can be written as

$$
\frac{\partial v}{\partial t}+\frac{\partial f_{i}}{\partial x_{i}}+\frac{\partial g_{i}}{\partial x_{i}}=0 \quad i=1,2,3
$$

in which the conservation variables, flux, and body force column vectors, as well as the viscous stress are defined as

$$
\begin{aligned}
& \boldsymbol{v}=\left[\begin{array}{lll}
\rho & \rho u_{j} & \rho E
\end{array}\right]^{T}, j=1,2,3 \\
& f_{j}=\left[\begin{array}{lll}
\rho u_{j} & \left(\rho u_{i} u_{j}+p \delta_{i j}\right) & u_{j}(p+\rho E)
\end{array}\right]^{T}, j=1,2,3 \\
& E_{j}=\left[\begin{array}{lll}
0 & \sigma_{i j} & \left(u_{i} \sigma_{i j}+k \frac{\partial T}{\partial x_{j}}\right)
\end{array}\right]^{T} \\
& f_{b}=\left[\begin{array}{lll}
0 & f_{b_{i}} & u_{i} f_{b_{i}}
\end{array}\right]^{T} \\
& \sigma_{i j}=\mu\left[\frac{\partial u_{i}}{\partial x_{j}}+\frac{\partial u_{j}}{\partial x_{i}}-\frac{2}{3} \frac{\partial u_{l}}{\partial x_{l}} \delta_{i j}\right] \quad l=1,2,3
\end{aligned}
$$

where $u_{i}$ are velocity components in the $x_{i}$ coordinate system; $\rho, p$, and $E$ are the density, pressure, and total energy respectively; $\mu$ is the dynamic viscosity; $k$ is the thermal

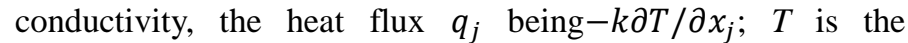
temperature; $\boldsymbol{f}_{b}$ represents the body forces.

The preceding equations are nondimensionalised for numerical calculations. In this process the governing equations remain in the same form excepting $g_{j}$, which becomes

$$
g_{j}=\left[\begin{array}{lll}
0 & \sigma_{i j} & \left(u_{i} \sigma_{i j}-q_{j}\right)
\end{array}\right]^{T}
$$

and also the viscous stress tensor and heat flux take the following form:

$$
\begin{aligned}
\sigma_{i j} & =\frac{\mu}{\operatorname{Re}}\left[\frac{\partial u_{i}}{\partial x_{j}}+\frac{\partial u_{j}}{\partial x_{i}}-\frac{2}{3} \frac{\partial u_{l}}{\partial x_{l}} \delta_{i j}\right] \\
q_{j} & =\frac{1}{\operatorname{RePr}} \frac{\partial T}{\partial x_{j}}
\end{aligned}
$$

in which the Reynolds number is defined as $R e=u_{\infty} L / v_{\infty}$; $v_{\infty}=\mu_{\infty} / \rho_{\infty}$ is termed the kinematic viscosity; $\operatorname{Pr}$ is the Prandtl number, $\operatorname{Pr}=v_{\infty} / \alpha_{\infty}$, with $\alpha_{\infty}=k /\left(\rho_{\infty} c_{p}\right)$ is the thermal diffusivity.

The Taylor's expansion of the solution $v(x, t)$ in the time domain, neglecting second order term and body forces, yields

$$
\Delta \boldsymbol{v}=-\Delta t\left[\frac{\partial f_{i}}{\partial x_{i}}+\frac{\partial \boldsymbol{g}_{i}}{\partial x_{i}}\right]_{(t)}
$$

in which $\Delta \boldsymbol{v}=\boldsymbol{v}(t+\Delta t)-\boldsymbol{v}(t)$. Applying Galerkin's spatial idealization $\boldsymbol{v}=\boldsymbol{a} \widetilde{\boldsymbol{v}}, \widetilde{\boldsymbol{v}}$ being the nodal values and $\boldsymbol{a}$ the shape functions vector, the flow equation can be expressed as ${ }^{7}$

$$
\begin{gathered}
\boldsymbol{M} \Delta \widetilde{\boldsymbol{v}}=-\Delta t\left[\frac{\partial u_{i}}{\partial x_{i}} \boldsymbol{M}+\boldsymbol{K}\right] \widetilde{\boldsymbol{v}}-\Delta t\left(\hat{\boldsymbol{f}}_{1}+\widehat{\boldsymbol{f}}_{2}\right)+\Delta t \widehat{\boldsymbol{R}}+ \\
\Delta t\left[\boldsymbol{K}_{\sigma}+\boldsymbol{f}_{\sigma}\right]
\end{gathered}
$$

in which $\boldsymbol{M}$ is the consistent mass matrix, $\boldsymbol{K}$ the convection matrix, $\hat{\boldsymbol{f}}_{1}, \hat{\boldsymbol{f}}_{2}$ the pressure matrices, $\boldsymbol{K}_{\sigma}$ the second-order matrix that includes viscous and heat flux effects, and $\boldsymbol{f}_{\sigma}$ the boundary integral matrix from second-order terms. Then,

$$
\begin{gathered}
\boldsymbol{M}=\int_{V} \boldsymbol{a}^{T} \boldsymbol{a} d V ; \quad \boldsymbol{K}=\int_{V} \boldsymbol{a}^{T} \bar{u}_{\boldsymbol{i}} \frac{\partial \boldsymbol{a}}{\partial x_{i}} d V ; \\
\widehat{\boldsymbol{f}}_{1}=\int_{V} \boldsymbol{a}^{T} \bar{p}_{i} \frac{\partial e_{i}}{\partial x_{i}} d V ; \quad \widehat{\boldsymbol{f}}_{2}=\int_{V} \boldsymbol{a}^{T} \bar{e}_{i} \frac{\partial e_{i}}{\partial x_{i}} d V ; \\
\boldsymbol{K}_{\sigma}=-\int_{V} \frac{\partial \boldsymbol{a}^{T}}{\partial x_{j}} e_{j} \sigma_{i j} d V-\int_{V} \frac{\partial \boldsymbol{a}^{T}}{\partial x_{j}} \boldsymbol{m}_{j} q_{j} d V ; \\
\boldsymbol{f}_{\sigma}=\int_{\Gamma} \boldsymbol{a}^{T} e_{j} \sigma_{i j} \hat{n} d \Gamma+\int_{\Gamma} \boldsymbol{a}^{T} \boldsymbol{m}_{j} q_{j} \hat{n} d \Gamma
\end{gathered}
$$

In these equations, $\bar{p}_{i}, \bar{u}_{i}, \overline{\boldsymbol{e}}_{i}$ are the average values; $\boldsymbol{e}_{1}=$ $\left[\begin{array}{lllll}0 & 1 & 0 & 0 & u_{1}\end{array}\right]^{T}, \boldsymbol{e}_{2}=\left[\begin{array}{lllll}0 & 0 & 1 & 0 & u_{2}\end{array}\right]^{T}, \boldsymbol{e}_{3}=\left[\begin{array}{lllll}0 & 0 & 0 & 1 & u_{3}\end{array}\right]^{T}, \widehat{\boldsymbol{R}}$ is the artificial dissipation, and $\boldsymbol{m}_{1}=\boldsymbol{m}_{2}=\boldsymbol{m}_{3}=\left[\begin{array}{llll}0 & 0 & 0 & 0\end{array}\right]^{T}$. Turbulence terms are included by modifying the viscous effects.

A novel two-step solution procedure ${ }^{17}$ is adopted for the flow equation, the inviscid solution being augmented with the viscous term and stabilized with artificial dissipation terms. Assuming,

then,

$$
\Delta \widetilde{v}=\widetilde{v}_{n+1}-\widetilde{v}_{n}
$$

$$
\boldsymbol{M}\left(\widetilde{\boldsymbol{v}}_{n+1}-\widetilde{\boldsymbol{v}}_{n}\right)=\frac{-\Delta t}{2}[c \boldsymbol{M}+\boldsymbol{K}]\left(\widetilde{\boldsymbol{v}}_{n+1}+\widetilde{\boldsymbol{v}}_{n}\right)-\Delta t\left(\hat{\boldsymbol{f}}_{1}+\right.
$$

which becomes

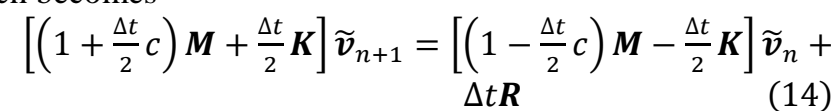

or

$$
\left[\boldsymbol{M}_{+}\right] \widetilde{\boldsymbol{v}}_{n+1}=\left[\boldsymbol{M}_{-}\right] \widetilde{\boldsymbol{v}}_{n}+\Delta t \boldsymbol{R}
$$

where

$$
\boldsymbol{R}=-\left(\hat{\boldsymbol{f}}_{1}+\hat{\boldsymbol{f}}_{2}\right)
$$

Let

$$
\boldsymbol{M}_{+}=\boldsymbol{D}_{+}+\boldsymbol{M}_{+}^{\prime}
$$

the matrix $\boldsymbol{D}_{+}$having diagonal elements. Equation (8) may then be solved as follows.

Step 1: Form

$$
\left[\boldsymbol{D}_{+}\right] \widetilde{\boldsymbol{v}}_{n+1}=\left[\boldsymbol{M}_{-}\right] \widetilde{\boldsymbol{v}}_{n}-\left[\boldsymbol{M}_{+}^{\prime}\right] \widetilde{\boldsymbol{v}}_{n+1}+\Delta t \boldsymbol{R}
$$

Step 2: Solve $\widetilde{\boldsymbol{v}}_{n+1}$ iteratively

$$
\begin{aligned}
& \widetilde{\boldsymbol{v}}_{n+1}^{(i+1)}=\left[\boldsymbol{D}_{+}\right]^{(-1)}\left\{\left[\boldsymbol{M}_{-}\right] \widetilde{\boldsymbol{v}}_{n}-\left[\boldsymbol{M}^{\prime}{ }_{+}\right] \widetilde{\boldsymbol{v}}_{n+1}^{(i)}+\Delta t(R+\widehat{\boldsymbol{R}}+\right. \\
& \left.\left.\boldsymbol{K}_{\boldsymbol{\sigma}}+\boldsymbol{f}_{\boldsymbol{\sigma}}\right)\right\}
\end{aligned}
$$

Step 3: If $\left\|\widetilde{\boldsymbol{v}}_{n+1}^{(\boldsymbol{i}+\mathbf{1})}\right\| \neq \operatorname{EPS} 1\left\|\widetilde{\boldsymbol{v}}_{n+1}^{(\boldsymbol{i})}\right\|$ go to Step 2.

Step 4: If $\left\|\widetilde{\boldsymbol{v}}_{n+1}^{(\boldsymbol{i}+\mathbf{1})}\right\| \neq \operatorname{EPS} 2\left\|\widetilde{\boldsymbol{v}}_{n+1}^{(\boldsymbol{i})}\right\|$ go to Step 1 .

Step 5: Repeat Steps 1 to 4 NITER times until desired convergence is achieved, that is until $\widetilde{\boldsymbol{v}}_{n+1} \approx \widetilde{\boldsymbol{v}}_{n}$; EPS1 and EPS2 are suitable convergence criteria factors, specified by the users.

The iterative process in Step 2 requires a small number of steps, usually 1 , and achieves a stable, convergent solution.

In regions of high pressure gradients, artificial dissipation term is applied to prevent oscillations near discontinuities. This is implemented by incorporating pressure-switched diffusion coefficients as appropriate. Thus,

$$
\hat{R}=\frac{C_{S} S_{e}}{\Delta t} M_{L}^{-1}\left[M_{c}-M_{L}\right] \tilde{v}_{n}
$$

in which $C_{S}$ is a shock capturing constant, $S_{e}$ is the averaged element value of the nodal pressure switch defined as 


$$
S_{i}=\frac{\left|\sum p_{i}-p_{j}\right|}{\sum\left(\left|p_{i}-p_{j}\right|\right)}
$$

and $M_{C}$ and $M_{L}$ are the consistent and lumped mass matrices respectively; $l$ is the node under consideration and $j$ are the nodes connected to $i$.

To obtain the viscous components, $\sigma_{i j}$ in Eq. (4) is written as

$$
\sigma_{i j}=-\frac{2}{3} \frac{\mu}{R e} \frac{\partial u_{l}}{\partial x_{l}} \delta_{i j}+\frac{\mu}{R e}\left(\frac{\partial u_{i}}{\partial x_{j}}+\frac{\partial u_{j}}{\partial x_{i}}\right)
$$

and the diffusion flux of the Navier-Stokes equation being

$$
\begin{array}{r}
g_{i}=\left(\begin{array}{lllll}
0 & \sigma_{i 1} & \sigma_{i 2} & \sigma_{i 3} & u_{j} \sigma_{i j}+\frac{1}{\operatorname{RePr}} \frac{\partial T}{\partial x_{i}}
\end{array}\right)^{T} \\
i=1,2,3 ; \quad j=1,2,3
\end{array}
$$

$\mu$ is the nondimensional viscosity term, whereas $R$ e and $P r$ are the Reynolds and Prandtl numbers, respectively. Next components of $\partial g_{i} / \partial x_{i}$ are evaluated term by term and then discretized by Galerkin approximation.

This procedure is adopted in the STARS-CFDSOL code ${ }^{1}$ that enables effective solution of the Naviar-Stokes equation in most flight regimes.

\section{NUMERICAL AND TEST RESULTS}

Accuracy ${ }^{18}$ of the STARS CFD code was verified pertaining to the Hyper-X flight vehicle, carrying the $X-43$ vehicle for subsequent hypersonic flight at Mach 5.0 and 7.0. Table 1 provides such a comparison of computational results and actual flight test data at various sensor locations; these data pertain to the ascent state of Hyper-X at Mach 0.9 and an altitude of $22,500 \mathrm{ft}$. Figure 1 provides a graphical depiction of comparison of the two sets of results, signifying accuracy of the relevant procedures. Also Table 1 shows the numerical values of flight test and computed aerodynamic pressures; excellent correlation is observed for primary data values; the last three values in the Table are comparatively small and hence prone to measurement inaccuracy. This code was next used, along with a variety of existing commercially available programs, to solve a practical project problem. The results of which were also compared to that obtained by actual flight and wind tunnel tests.

The Gulfstream GIII airplane (Gulfstream Aerospace Corporation, Savannah, Georgia), currently undergoing flight tests $^{19}$ at NASA AFRC, was chosen as the example problem for verification purposes. The GIII business jet as shown in Figure 2 is being modified and instrumented by NASA's Armstrong Flight Research Center to serve as a test bed for a variety of flight research experiments, in support of the Environmentally Responsible Aviation (ERA) project. The twin-turbofan aircraft provides long-term capability for efficient testing of subsonic flight experiments for NASA, the U.S. Air Force, other government agencies, academia, and private industry.

The wing span of the GIII aircraft is 23.7226 meter with sweep angle 27.66 degree. The airfoil section is a NACA 0012 modification. The aerodynamic model of the GIII wing used in the CFDSOL and MG solutions is shown in Figure 3; only the right wing section was used for CFD analysis. Total number of CFD mesh using triangular element on wing surface is $31 \mathrm{k}$ for coarse mesh and 59k for finer mesh. Total number of 3-D CFD mesh using tetrahedron element in aerodynamic domain is $1.2 \mathrm{~m}$ for coarse mesh and $2.8 \mathrm{~m}$ for finer mesh.

. The flight condition was for Mach 0.7 and angle of attack $\alpha=$ 3.92 degrees. Table 2 provides extensive description of relevant analyses hardware employed for each of the participative code and solution CPU time for a converged solution. The STARS has two solution option modules, namely CFDSOL and MG and both appear to be competitive in terms of solution time, accuracy, grid size and CPU numbers.

Figures 4 to 6 depict pressure $\left(\mathrm{C}_{\mathrm{p}}\right)$ distribution around the wing airfoil cross section at the wing $368.3 \mathrm{~cm}, 584.2 \mathrm{~cm}$ and $1003.5 \mathrm{~cm}$ span wise locations. Further, the wind tunnel and actual flight test results are also shown for comparison and validation purpose. Due to the proprietary nature of the wind tunnel and fight test data, actual scales on the figures cannot be shown. Each of the codes shows reasonable correlation; solution of the CFDSOL and MG codes appear to be rather close to the two test results.

Figure 7 depicts the $C_{p}$ distribution along the airfoil at different span locations.

\section{CONCLUDING REMARKS}

The paper presents detailed comparison of solutions of the GIII aircraft wing obtained by a number of commercially available CFD codes as well as two AFRC in-house codes that use a finite element fluids discretization employing unstructured grids; related formulations of the novel CFDSOL code are also presented in detail. Importantly these solutions are compared with actual flight and also wind tunnel test data. Each of the codes shows reasonable correlation; solution of the CFDSOL and MG codes appear to be rather close to the two test results, particularly around the leading edge; further, use of a single CPU to derive solutions testifies to their cost effectiveness.

\section{REFERENCES}

1. Gupta, K. K. and Meek, J. L., A Primer on Multidisciplinary Finite Element Engineering Analysis, AIAA Education Series, Sept. 2013.

2. Prinkey, M., Shahnam, M., and Rogers, W. A., "SOFC FLUENT Model Theory Guide and User Manual," Release Version 1.0, FLUENT, Inc., 2004.

3. FUN3D Manual: 12.4-69883, Biedron, R. T., Derlaga, J. M., Gnoffo, P. A., Hammond D. P., Jones, W. T., Kleb B., Lee-Rausch E. M., Nielse E. J., Park M.l A., Rumsey C. L., Thomas J. L., and Wood W. A., NASATM-2014-218179, 2014.

4. Johnson, F. T., Tinoco, E. N., and Yu, N. J., "Thirty Years of Development and Application of CFD at Boeing Commercial Airplanes, Seattle," Computers \& 
Fluids, Vol. 34, Issue 10, December 2005, pp. 11151151.

5. Pandya, M. J., Frink, N. T., and Noack, R. W, "Progress Toward Overset-Grid Moving Body Capability for USM3D Unstructured Flow Solver," $17^{\text {th }}$ AIAA CFD Conference, June 8-9 2005, Toronto, Canada.

6. CD-adapco, STAR-CCM +

7. Smith, G. D., Numerical Solution of Partial Differential Equations: Finite Difference Methods, $3^{\text {rd }}$ edn, Clarendon Press, Oxford, 1985.

8. Versteeg, H. K., and Malalasekera, W., An introduction to Computational Fluid Dynamics- The Finite Volume Method, $2^{\text {nd }}$ edn., Pearson/Prentice Hall, 2007.

9. Jameson, A., and Caughey, D., "A Finite Volume Method for Transonic Potential Flow," AIAA paper 77-635, $3^{\text {rd }}$ AIAA Computational Fluid Dynamics Conference, Albuquerque, New Mwxico, 1977.

10. Ferziger, Joel H., and Peric, Milovan, Computational Methods for Fluid Dynamics, $3^{\text {rd }}$, rev. edition, Springer, 2002.

11. Fletcher, C. A. J., Computational Techniques for Fluid Dynamics, Vols I and II, springer-Verlag, Berlin, 1991.

12. Zienkiewicz, O. C. and Taylor, R. L., The Finite Element Method - Vol. 2: Solid and Fluid Mechanics, McGraw-Hill, New York, 1991.

13. Donea, J., "A Taylor-Galerkin Method for Convective Transport Problems", International Journal of Numerical Methods in engineering, Vol. 20, No. 1, pp. 101-119, 1984.

14. Peraire, J., Peiro, J., Formaggia, L., Morgan, K., and Zienkiewicz, O. C., "Finite Element Euler Computations in three dimensions," International Journal of Numerical Methods in engineering, Vol. 26, No. 10, pp. 2135-2159, 1988.

15. Morgan, K., Peraire, J., and Peiro, J., "The Computation of Three Dimensional Flows using Unstructured Grids", Computational Methods in Applied mechanics and engineering, Vol. 87, No. 3, pp. 335-332, 1991.

16. Spalart, P. R., and Allwaras, S. R.,"A One-Equation Turbulance Model for Aerodynamic Flows," AIAA Paper 92-0439, 1992.

17. Gupta, K. K. and Meek, J. L., Finite Element Multidisciplinary Analysis, AIAA Education Series, Sept, 2003.

18. Gupta, K. K. and Bach, C., "Computational Fluid Dynamics - Based Aeroservoelastic Analysis with Hyper-X Applications", AIAA Journal, Vol. 45, No. 7, pp 1459-1471, 2007.

19. Baumann, E., Hernandez, J., and Ruhf, J., "An Overview of NASA's SubsoniC Research Aircraft Testbed (SCRAT)," AIAA-2013-5083, 2013. 
Table 1 Comparison of computed and flight test measured pressure data for the Hyper-X/X-43 vehicle

\begin{tabular}{cccc}
\hline \hline \multirow{2}{*}{$\begin{array}{c}\text { Sensor } \\
\text { point }\end{array}$} & Flight test & CFD computed & $\begin{array}{c}\text { Percent } \\
\text { difference }\end{array}$ \\
\cline { 2 - 4 } & 0.01165 & 0.01193 & 2.34 \\
\hline 001 & 0.01227 & 0.01164 & 6.12 \\
\hline 003 & -0.00167 & -0.00096 & 42.12 \\
\hline 007 & -0.00108 & -0.00268 & 147.99 \\
\hline 085 & 0.00048 & -0.00055 & 2.56 \\
\hline 090 & & & \\
\hline
\end{tabular}

Table 2 CFD Solvers Comparison

\begin{tabular}{|c|c|c|c|c|c|c|}
\hline CFD Solver & Flow Equation & Platform & $\begin{array}{l}\text { No. of } \\
\text { CPU }\end{array}$ & Total CPU time & Grid Size & Note \\
\hline STARCCM+ & $\begin{array}{l}\text { RANS, finite } \\
\text { volume, K- } \\
\text { omega SST } \\
\text { turbulence }\end{array}$ & Cluster & $\sim 80$ & $\begin{array}{l}6 \mathrm{hr}, 40 \mathrm{~min}(533 \\
\text { cpu hours) - } \\
3000 \text { iterations }\end{array}$ & $\begin{array}{c}7.2 \mathrm{M} \\
\text { polyhedra/prismatic } \\
\text { for half model } \\
\text { without T-tail }\end{array}$ & $\begin{array}{c}\text { number of } \\
\text { processers is } \\
\text { an estimate, } \\
\text { and the time } \\
\text { is an estimate } \\
\text { for that } \\
\text { number of } \\
\text { processors }\end{array}$ \\
\hline STARS (MG) & $\begin{array}{l}\text { Euler, finite } \\
\text { element }\end{array}$ & $\begin{array}{l}\text { Dell M620 8GB } \\
\text { Ram, } 64 \text { bit }\end{array}$ & $\begin{array}{c}\text { Intel } \\
\text { Core i7 } \\
@ 2.67 \\
\mathrm{GHz}\end{array}$ & $\begin{array}{l}2.8 \mathrm{hr},(100 \\
\text { steps, } 25 \text { inner } \\
\text { cycles) }\end{array}$ & $\begin{array}{l}\text { 1.2 M Tetrahedrons } \\
\text { for wing only }\end{array}$ & \\
\hline $\begin{array}{c}\text { STARS } \\
\text { (CFDSOL) }\end{array}$ & $\begin{array}{l}\text { Full N-S, finite } \\
\text { element }\end{array}$ & $\begin{array}{l}\text { Dell M620 8GB } \\
\text { Ram, } 64 \text { bit }\end{array}$ & $\begin{array}{c}1 \text { Intel } \\
\text { Core i7 } \\
@ 2.67 \\
\mathrm{GHz} \\
\end{array}$ & $\begin{array}{l}13.8 \mathrm{hr}(10000 \\
\text { steps) }\end{array}$ & $\begin{array}{l}2.8 \mathrm{M} \text { Tetrahedrons } \\
\text { for wing only }\end{array}$ & \\
\hline USM3D & $\begin{array}{l}\text { Full N-S, finite } \\
\text { volume }\end{array}$ & Mac 64 bit & 2 CPUs & $16 \mathrm{hr}$ & $\begin{array}{l}1.9 \mathrm{M} \text { cells for half } \\
\text { model without T-tail }\end{array}$ & \\
\hline TRANAIR & $\begin{array}{c}\text { Full potential + } \\
\text { viscosity } \\
\text { (boundary } \\
\text { layer) }\end{array}$ & $\begin{array}{c}\text { Linux } \\
\text { Workstation }\end{array}$ & $1 \mathrm{CPU}$ & $2 \mathrm{~h}, 28 \mathrm{~min}$ & $\begin{array}{l}\text { 1.7M cells for full } \\
\text { model }\end{array}$ & \\
\hline
\end{tabular}




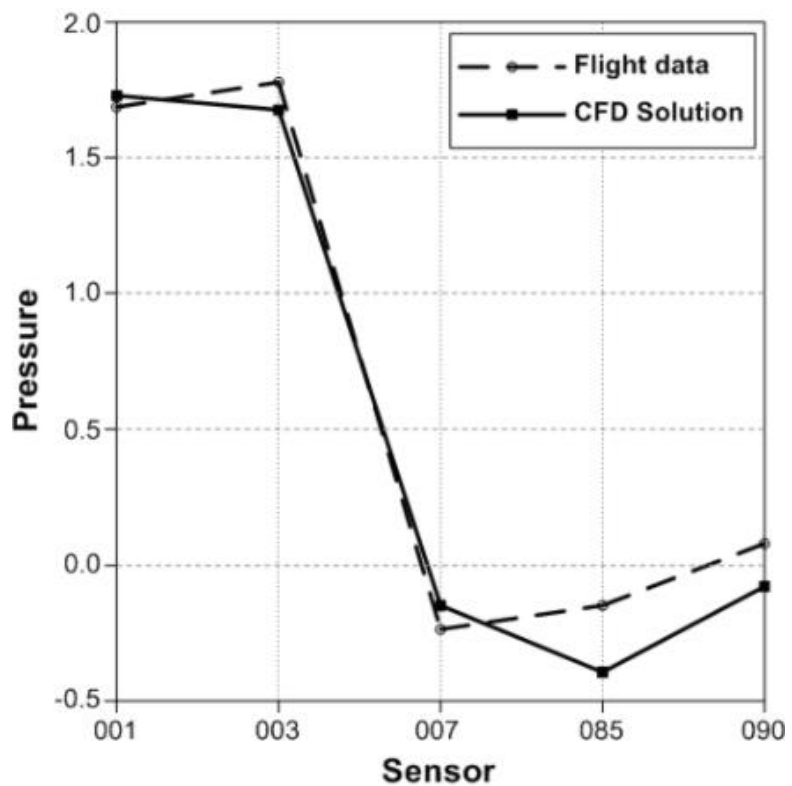

Fig. 1 Comparison of flight measured and calculated (CFD) pressure on Hyper-X/X-43 vehicle

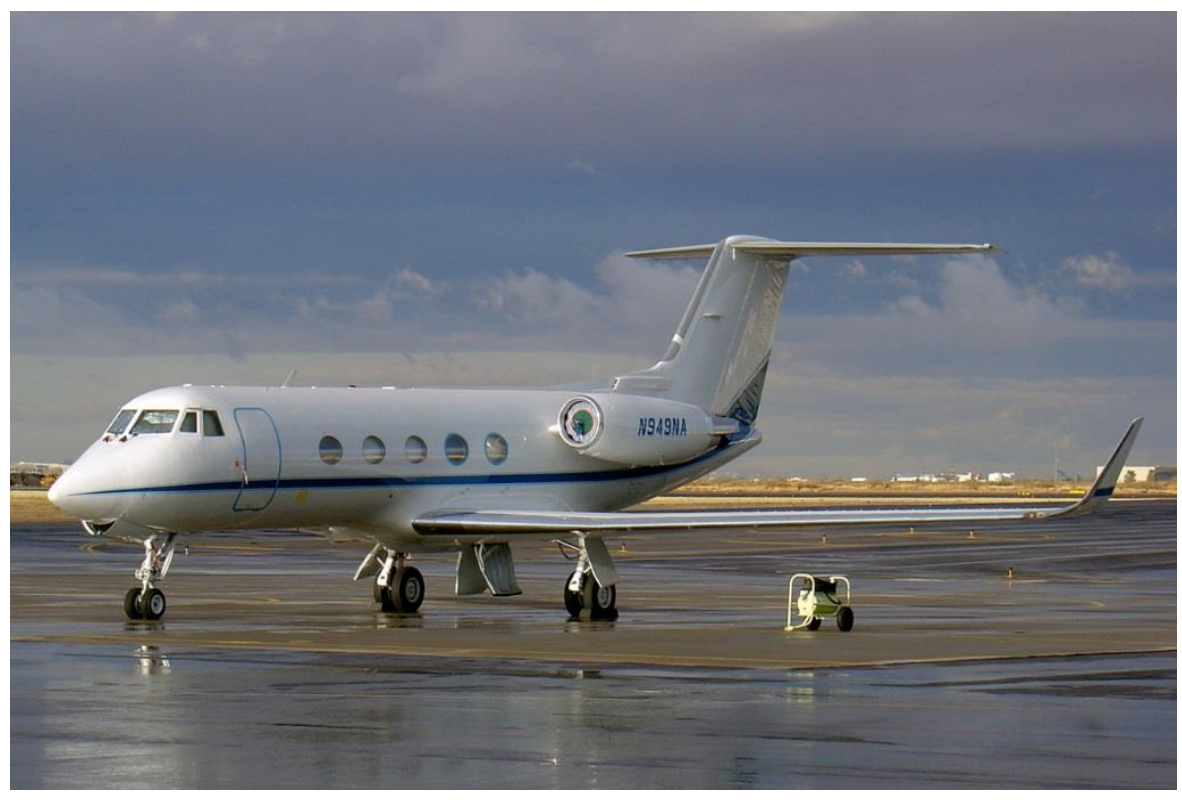

Fig. 2 Grumman Gulfstream III (GIII) business jet. 


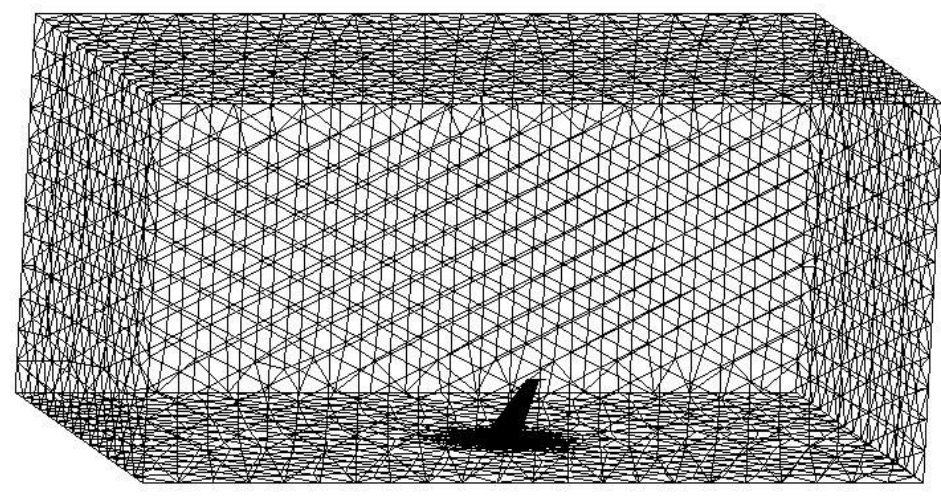

(a) Domain Discretization

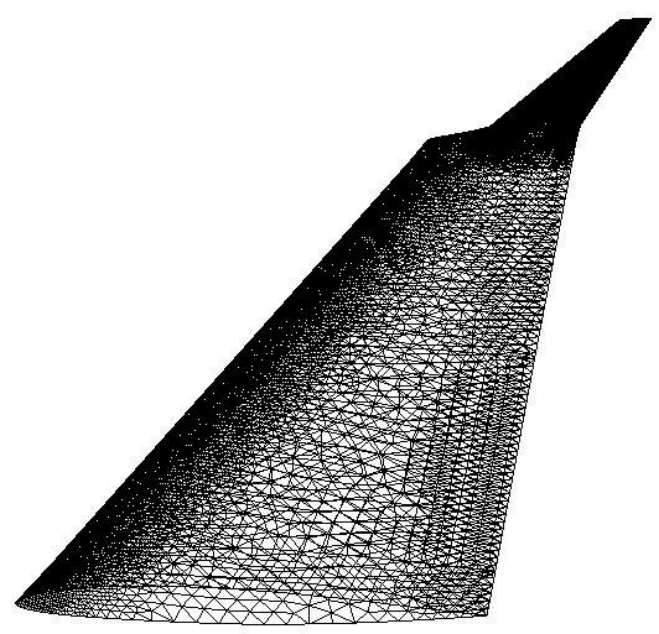

(b) Surface Mesh

Fig. 3 Aerodynamic model of the GIII aircraft wing. 


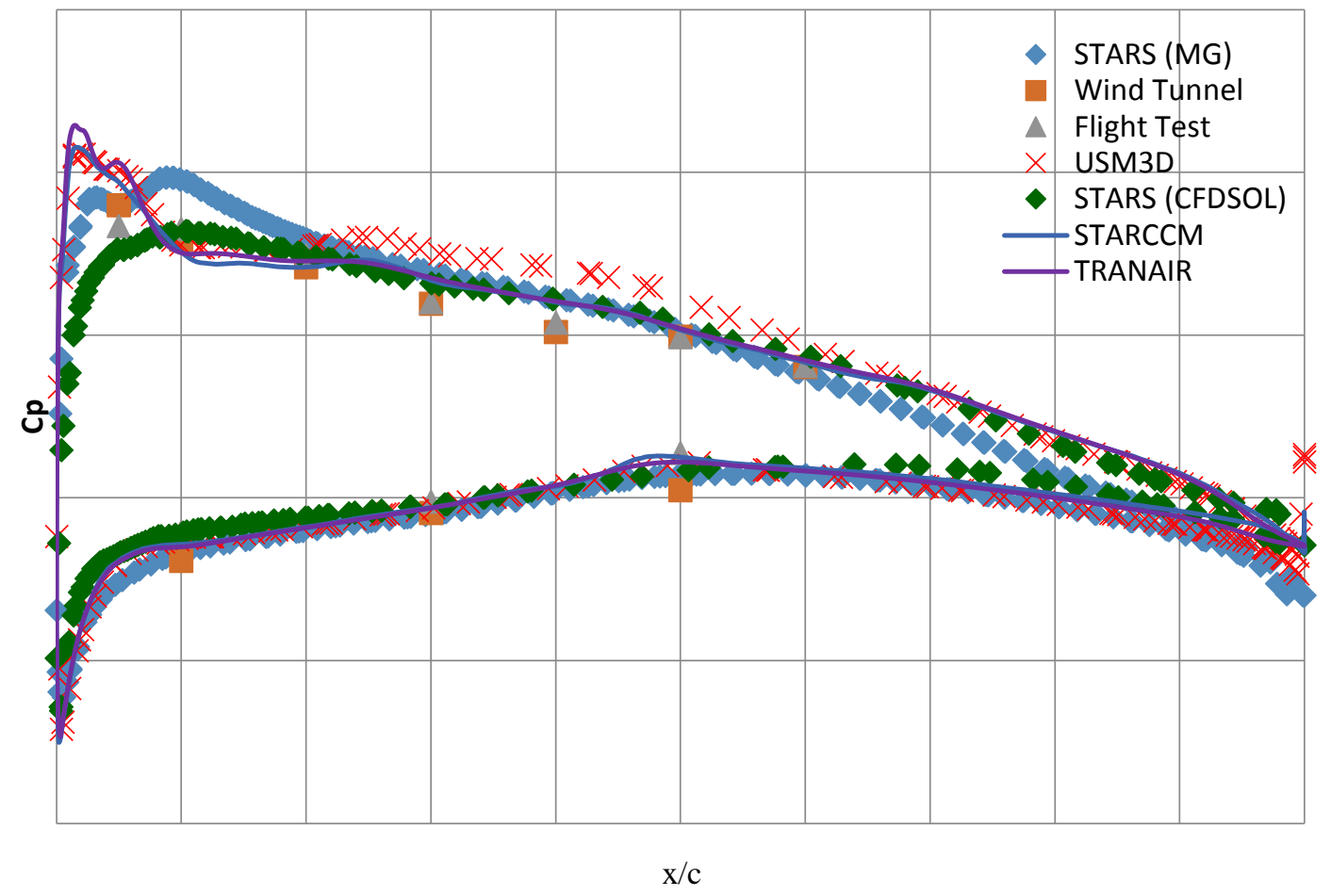

Fig. $4 \mathrm{C}_{\mathrm{p}}$ plot at span station 145

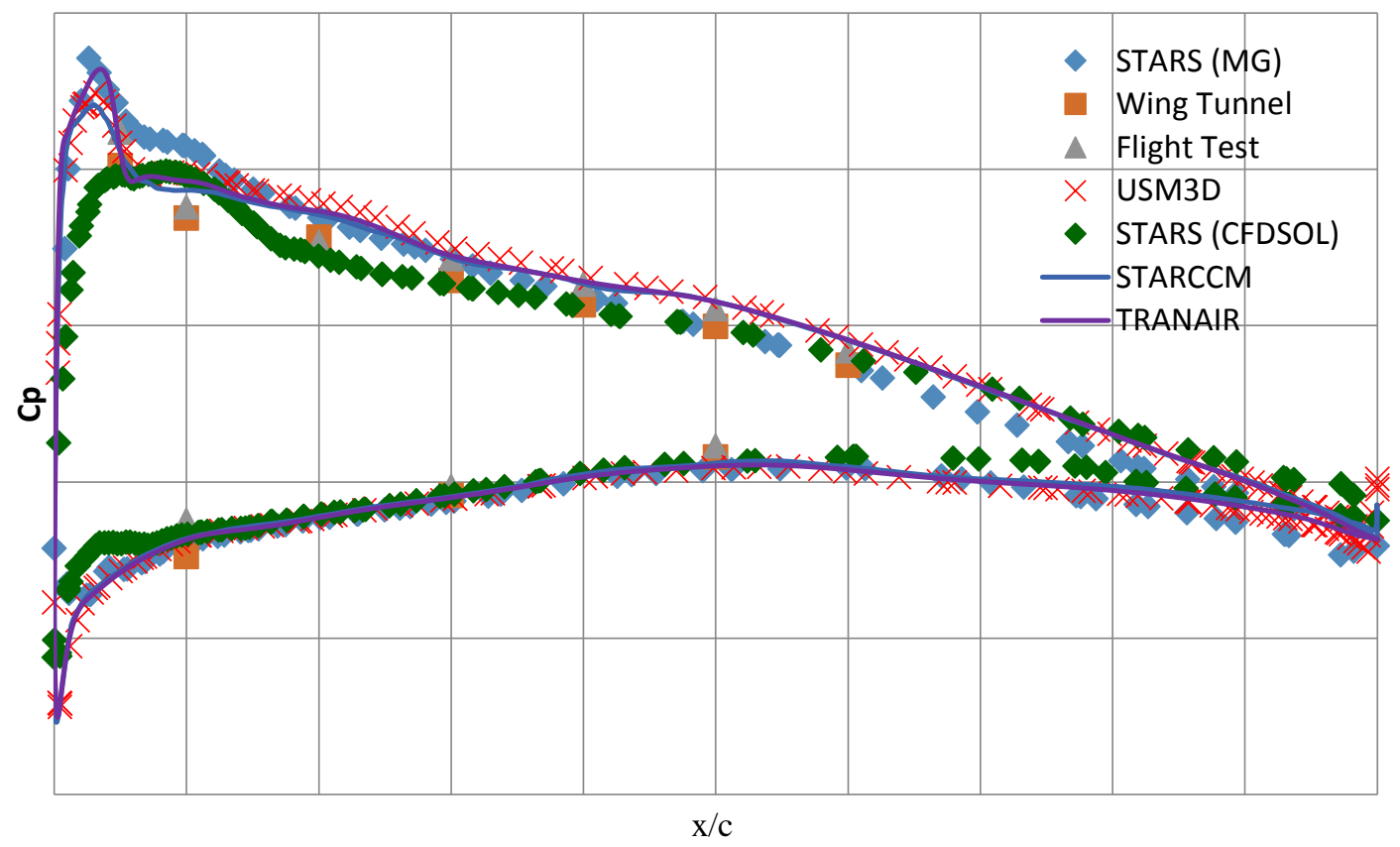

Fig. $5 \mathrm{C}_{\mathrm{p}}$ plot at span station 230 


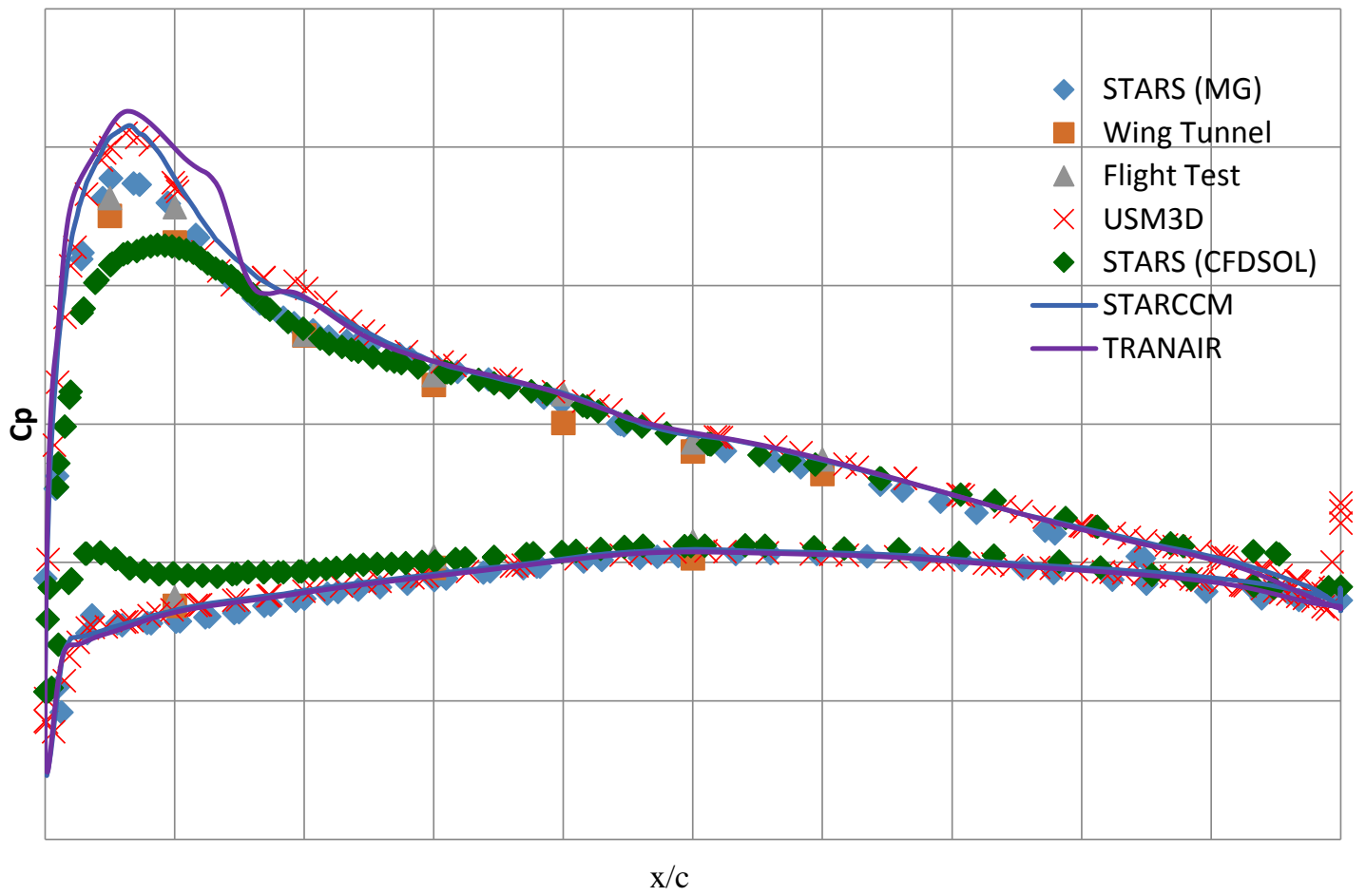

Fig. $6 \mathrm{C}_{\mathrm{p}}$ plot at span station 385 .

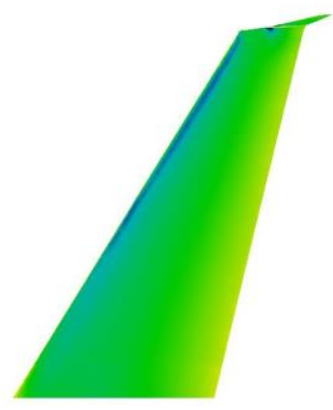

(a) $C_{p}$ distribution on wing surface

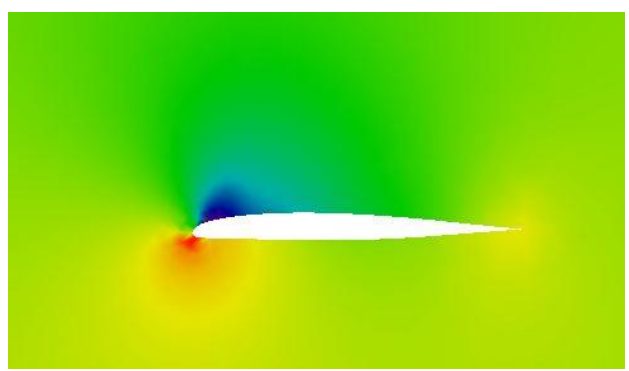

(c) $\mathrm{C}_{\mathrm{p}}$ at station 230

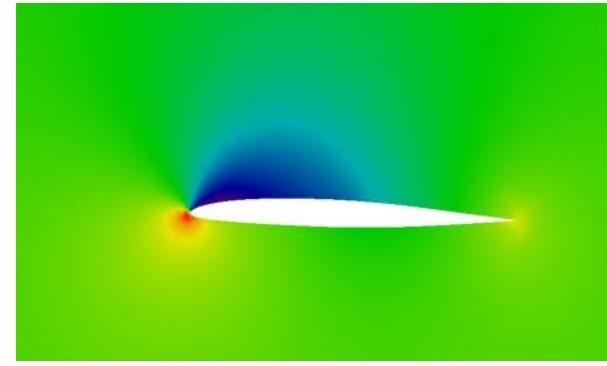

(b) $C_{p}$ at station 145

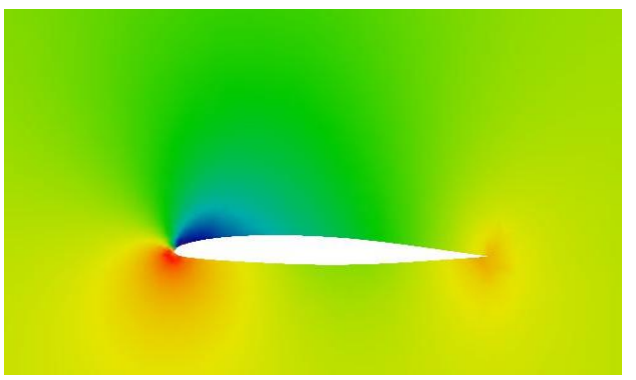

(d) $C_{p}$ at station 385

Fig.7 Typical $C_{p}$ plots at various locations 